\title{
The Ethics and the Practical Reasoning: About Common Sense and Programming
}

\author{
Perspectivismo con objetividad, causal y temporal
}

ITAMAR SOARES VEIGA*

\begin{abstract}
: this paper discusses the issue of practical reasoning, considering it as a field of study shared among three areas: ethics, common sense and programming languages. It questions the exclusive connection of practical reasoning to the area of ethics, and seeks to show through analysis of examples that other areas of common sense and programming languages also have important elements that characterize practical reasoning. We conclude that practical reasoning cannot be assumed solely from ethics, but it should open a research through the plurality of philosophical discussion.

Key words: argument, ethics, means-end, action, programming.
\end{abstract}

\begin{abstract}
Resumen: en este trabajo se analiza la cuestión de la razón práctica, considerándola como un campo de estudio compartido entre tres zonas: ética, sentido común, lenguajes de programación. Cuestiona la conexión exclusiva del razonamiento práctico para el área de la ética, y trata de mostrar a través del análisis de ejemplos que otras áreas de sentido común y de los lenguajes de programación tienen elementos importantes en el razonamiento práctico. Llegamos a la conclusión de que el razonamiento práctico no se puede asumir exclusivamente de la ética, pero debe abrir una investigación a través de la pluralidad de la discusión filosófica.
\end{abstract}

Palabras clave: argumento, ética, medios y fines, acción, programación.

The practical reasoning owns as main characteristic a thread of premises which conduct to a conclusion, this conclusion aims an action. This sort of reasoning is currently a fertile field of studies. We highlight some common elements such as: the separation between a group of premises and a conclusion, therefore a separation between precedent and consequent, the importance of the relation between means and ends, and the determinations which rule the inferential procedures.

However, despite these so called common elements, the knowledge areas which use practical reasoning assume certain distance from each other. Such distance is easily noticed in the effort that each area performs to delimit the components of their argumentative

Recibido: 31/05/2014. Aceptado tras reelaboración: 27/08/2018.

* Profesor en la Universidad de Caxias do Sul - Brasil, actúa en el programa de postgrado. Sus líneas de investigación son: filosofía y tecnología, problemas interdisciplinarios de ética. Sus artículos académicos más recientes versan sobre los temas inteligencia artificial y biopolítica. Autor de "Cotidiano y la caída - un análisis del apartado 38 de Ser y tiempo" (2012, libro en portugués), correo electrónico: inpesquisa@yahoo.com.br. 
processes. This delimitation process results not only in the enlightenment of argumentative components, but also in the enlightenment of a distinctive scope of a kind of reasoning as a whole face each of the involved areas, distinguishing each of them. What areas are these?

From the minimum classification that practical reasoning is an inferential process between precedent and consequent, in which the conclusion demands an action, we are able to identify three knowledge areas: the common sense area, the ethics area and the programming languages area. Each of them owns its specific practical reasoning. And, in these three areas, the common characteristics are maintained. That is, in these three areas there is an inferential process, which is a passage from the premises to a conclusion, and the conclusion is a specific action. The deepening of this common characterization will show the details of similarities and differences between these three areas.

To perform this deepening we must first clarify the following characterization which connects them:

(a) The common sense area will be characterized as the field of development of a means and ends relation, which has, as center of attention, a very restrict problem. Such restriction is conditioned by the scope where the problem is. This scope is the one where the agent holds full knowledge of all aspects at stake within this same field. Example: (1) I have to go out, but (2) it's raining, (3) so I take an umbrella, or another example, related to an Aristotle tradition: "Every man must go for a walk; I am a man. Therefore I must go for a walk"1;

(b) In the area of ethics a background reflection determines the inferential movement of the argument (the passage of precedent to consequent), and results in a conclusion that aims an action. This constitutes an argumentative core which confers the designation of the reasoning as moral-practical reasoning. Ethics, more precisely, remains in the reflection that determines the action, or a change of state of mind or even of intention, of the agent. The central characteristic of the practical reasoning in ethics is that there is an inflection on the premises and, therefore, on the means and ends relation. This relation is dislocated from its component character in relation to practical reasoning. A possible example is the one originated from the thesis which defends that certain reasons are assembled to premises ${ }^{2}$.

1 This is a reformulation made by D.J. Allan, of one of the forms of Aristotle's practical syllogism. This example can be complex than the previous one, due to its possible connection to an action characterized as "moral" action: "The Practical Syllogism". In: Mansion, S. Autour d'Aristotes. Louvain, 1955, p.336s. In addition, Allan also introduced a conception where there are two incompatible practical reasoning: one that orients itself by means and ends and other that orients itself by the appliance of a general rule. The general rule is explicit in the concept of prudence and, hence, enters into ethics universe. Allan's work has suffered much criticism, including accusations from Gauthier and Jolyf in Gauthier, R. A.; Jolif, J. Y. L'Etique a Nicomaque (comentaire). Paris: J. Vrin, 1959, v2, p.209s, who disagree with the division between both types of practical reasoning due to their incompatibility. Furthermore, there is also the accusation made by Wiggins, who alleges that these practical reasoning found by Allan are, in fact, complementary, cf. Wiggins, D. "Deliberation an Practical Reasoning". In: Millgram, E. (ed.) Varieties of Practical Reasoning. Cambridge: MIT Press, 2001, p.286-290.

2 This is a debate about the rationality requirements and whether they are normative. For an analysis about the problems regarding the normativity of these rationality requirements, see the discussion between John Broome and Joseph Raz in Raz, J. "The Myth of Instrumental Rationality", Journal of Ethics and Social Philosophy. April, v.1. 2005a, and in the Symposium of the same year: Broome, J. "Have We Reason to Do as Rationality Requires? A Comment on Raz". In: Journal of Ethics and Social Philosophy. Volume 1, Symposium I, issue 1, April, 2005, reply from Raz, in Raz, J. “Author's Reply: Joseph Raz, 'Instrumental Rationality: A Reprise'”. 
Due to these reasons, the rational agent modifies his will and acts according to reason or a rational will. Thus, the ethical inflection lies on the wider consideration that the agent must act according to these reasons which are considered by the agent. In this case, the moral action follows a theory of rationality or practical reason. Yet, this direction can be objected, because, as the flank of practical reasoning is open to ethics, other ethical currents can present themselves. This means: it is possible to add another direction to the moral-practical reasoning: the action can follow the emotion. A more detailed analysis about this ethical inflection, in both ethical currents: reasons or emotion, can be found in the inferential process of practical reasoning, which will be analyzed ahead.

(c) In the area of programming languages, we have a diversified appropriation of resources developed by philosophy and by mathematics and even from other areas. There is a basic diversity in the Artificial Intelligence, which is expressed in different platforms ${ }^{3}$. Nevertheless, the priority now is to point out that in the Artificial Intelligence area we can also find the need to adopt some sorts of reasoning to solve practical problems, or in other words, sorts of reasoning which result in conclusions that lead to an action.

As a prior conclusion, we can assert that, all of these three areas develop practical reasoning from diverse foundations. These type of reasonings have similar characteristics, as they are classified as practical. Yet, the classification of their different foundations is not easy, because, inside the same area, there are distinct means of possible practical reasoning and, also, different means of conducting their argumentative processes. On this diversity, the foundations of each area can only be classified generically. Let's proceed with this presentation according to each sort of practical reasoning separately.

In (a), the basis which supports the type of practical reasoning developed in the common sense area, refers to a group of cultural or social elements, or simply traditional elements from a community. These elements establish the parameters which intervened in the formation of premises and their thread. From this intervention, the basic structure of the practical reasoning directs the focus at the means and ends relation. The operational character of this reasoning aims the application to instant problems, specified within a known scope, which is, in the end, the community itself. The absence of the unknown is one of the main characteristics of the common sense area, consequently, the foundation of these sorts of practical reasoning deals only with what is already known.

In: Journal of Ethics and Social Philosophy, Volume.1, Symposium 1, issue 1. April, 2005b. Broome and Raz, agree that there is no "boostrapping" of reasons. Where, these reasons, would establish a "duty" of acting. The authors acknowledge Bratman's contribution in Bratman, M. E. Intentions, Plans, and Practical Reason. Cambridge: Massachusetts University Press, 1987, p.23-27 and also p.42-43. According to Bratman, the agent is not able to make his/her intention become a reason that compels him/her to act.

3 These platforms are the constructions, in programming language, which support different systems. The systems, when they involve a community of artificial agents, are considered to be "multi-agents systems". A detailing about multi-agents systems can be found in the bulky work of Russell, S.; Norvig, P. Artificial Intelligence: a modern approach. New Jersey: Prentice Hall, 2010, $3^{\text {a }}$ ed., p.34-59. Each system has a determined architecture. The classifications of these architectures can be found in Knapik, M.; Jonhson, J. Developing Intelligent Agents for Distributed Systems: Exploring, Architecture, Technologies, and Applications. MacGraw-Hill, 1998, p.151192. Finally, a common thematization between architectures and multi-agents systems is found in Wooldbridge, M.e Jennings, N. "Intelligent Agents: Theory and Practice", Knowledge Engineering Review, January, 1995, v.10:2, p.130-139. 
Foundation of (b): the programming languages area is connected to processes and resources of a specific programmable language. There is a previous determination that provides meaning to the establishments of conventions which will be used. The basis, in this particular case, is built formally, and influences on the possible flexibility of the language, which will be used operationally to solve practical problems. Consequently, in a lower level ${ }^{4}$, the choice of a certain language influences on the aims which can be achieved by the same language, but the aims horizon remains open. This opening allows us to show an important difference between the programming languages and the common sense regarding the problem solving: the programming languages can operate with inedited problems that have unpredictable, unknown content, or a problem lacking information. The common sense only operates with one scope and one problem whose contents are known.

In (c): the area of ethics a determined reflexive-philosophical basis stands out. In this area, the actions of practical reasoning are identified as moral. We denominate the theoretical-philosophical basis as a "background reflection" or "ethical reflection". The ethical reflection constitutes a speech with a set of philosophical concepts which justify why an action can be considered morally good or not. In the execution of the sorts of reasoning developed in an ethical reflection, the "determination" of the reflexive-philosophical basis adopted is present, and the practical reasoning can be entitled as "moral-practical reasoning". Besides, the reflexive-philosophical basis of ethics represents an inflection about the general theme of practical reasoning. For the adoption of this reflection pre-conditions the relations between means and ends, and in this pre-conditioning, is possible to present an one-sided comprehension for every practical reasoning, considering it from its one-sidedness, just as a "moral-practical" reasoning. In the philosophical tradition, there is a custom of annulling the space for the common and the programming languages approaches regarding practical reasoning. Both areas perform reasoning using argumentative processes which conduct to an action, but, we cannot affirm that, under all circumstances, the practical reasoning is moral-practical reasoning. Therefore, the action, and the fact that a sort of reasoning has been developed, enlarges the possible classification of what is and what is not "practical reasoning". And, in this sense, every time we find the word "practical reasoning" in a text, we should be cautious not to immediately classify it as been connected to the scope of moral action.

The justification to adopt diverse approaches of the moral-practical reasoning, that is, from areas other than ethics, is a product of the questioning on the strict connection between practical reasoning and the ethics. The present article presents several subsidies for the untying of the practical reasoning and the ethics, keeping such connection, only in one of the cases. Such untying must have as positive effect, the enrichment of the philosophical debate on the practical reasoning, in general, and preparation of the discussion in a new field of knowledge: that of the programming languages.

To achieve this enriching untying we will proceed the following way: firstly, we will separate and regroup the areas; secondly, we will analyze the argumentative constitution of

4 The expression "in a lower level" refers to a classification of computing languages: the low level languages are the ones closer to the machine language, whereas the "high level" languages are the ones that are built on low level languages which correspond to each other. 
the sorts of practical reasoning, underlining the relations between the premises and conclusions; in third place, we will pursue the recovery of a wider sense of practical reasoning, allowing a new focus on the philosophical analysis, routing our conclusion.

The division and reunification of the three areas: ethics, common sense and programming languages will be in only two groups. The ethics must have a group itself, and the common sense will be clustered with the programming languages. The underlying thesis of this division and reunification is that such configuration reflects the structure of internal reasoning of these areas. We will pursue the justification of this thesis through examples.

It should be noted that the general structure of reasoning consists of three propositions (or clauses) and an inferential process which shows the passage from the precedent to the consequent. This passage, which has different bases, modifies the way we treat propositions in the inferential passage itself. This modification reflects an influence on the content of propositions, such influence is explained by its own bases, and distinguishes each area profile. The distinction of these profiles, notwithstanding, allows us to associate the common sense and the programming language areas without any significant losses of identity, besides, it allows us to separate the area of ethics. Ultimately, from this division and reunification we have two groups.

\section{First group: the ethical reflection and the moral action}

The first group includes the practical reasoning developed in the area of ethics. This practical reasoning holds, in its inferential process, at least one proposition that expresses the connection with a theoretical and philosophical base. In other words, this connection stands for the adoption of or commitment with an ethical reflection developed by a philosopher. Thus, from a structural point of view, it means that, at least one proposition, whether it is of the precedent or the consequent, allows a classification of the action from the practical reasoning as a moral action.

At that, the structure of the reasoning enables us to talk about its parts, based on what its propositions say. The conclusions of the practical reasoning in the area of ethics result in an action description, or in a mandatory action, or even in the expression of an intention to $\operatorname{act}^{5}$, in which all these actions are characterized as moral. All these different acts: "describe", "have the obligation to..." and "intend" are liable to be simply classified: the description of an action is a report; the obligation of an action is the linguistic expression of this obligation; the intention to act is the linguistic expression of the mental state (or even, motivational state) of acting. The unity of these three different linguistic forms is the ethical reflection that is represented in the propositions content. Therefore, the passage from the precedent to

5 Cf. Streumer: "I think, is that there are different kinds of practical reasoning: reasoning that concludes with a belief about reasons for action or about what we ought to do, reasoning that concludes with an intention, and reasoning that concludes with an action. These processes of reasoning often succeed each other and, if they do so immediately, they can be said to form one continuous process of practical reasoning. But these process may not always succeed each other immediately, and practical reasoning can also result in the non-performance of an action, in giving up an intention, or in giving up a belief about reasons for action or about what we ought to do." Streumer, B. "Practical Reasoning". In: O’Connor, T.; Sandis, C. (eds.) The Blackwell Companion to the Philosophy of Action. Oxford: The Blackwell Publishing, 2010, p.249. 
the consequent characterizes the practical reasoning, with such content and linguistic forms, as "moral-practical reasoning".

To explicit, we will present this first example:

(1.a) Act as though your action were to be considered a universal maxim.

(1.b.) There is an elder facing hardship to cross a busy street, and I am able to help him [or: there is a clear situation where an ethical question is involved].

(1.c) I help the elder cross the street (description of an action), or

(1.d) I must help this person cross the street, expression of an obligation or description of a mental state or intention. Or in (1.c) and (1.d) I have an action face the ethical question involved (1.b).

Both propositions, above (1.c) and (1.d), can be considered as different versions of the same conclusion. They are not opposite to each other, not even exclusionary, but only different. The further version (1.d) is used in order to behold the expression of a duty or description of the mental state of the agent who feels compelled to act, in this case, there isn't an action itself, but the linguistic expression of the obligation. It means that the agent can have as a conclusion the expression of the duty to act or the expression of his intention to act, in this last case, the intention implies a change in his mental state ${ }^{6}$. At long last, we can formalize the argument (1) this way:

$\left[\mathrm{p}^{\wedge}\left(\mathrm{q}^{\wedge} \mathrm{r}\right)\right] \rightarrow \mathrm{s}$

- where $\mathrm{p}=(1 . \mathrm{a}) ; \mathrm{q}^{\wedge} \mathrm{r}=(1 . \mathrm{b}$, compound proposition) and $\mathrm{s}=(1 . \mathrm{c}$ or $1 . \mathrm{d})$.

- and, in a natural language: "if my action must be in such a way to be considered a universal maxim, and there is an elder facing hardship to cross the street, who I can help, so I help him cross the street (describing an action), or I must help (expressing an obligation) or I want to help (expressing a mental status which reveals an intention)".

The using of this formalization serves solely to clearly show the relations between the premises, where the precedent and the consequent differ, in addition to the inferential passage. The conjunction between the parentheses of " $\mathrm{q}$ " and " $\mathrm{r}$ " has to be true so that the precedent is also true. However, this formal exposition shows some important difference. Formally, we could have a false proposition and the conjunction between parentheses also false, and, nevertheless, the conclusion could be true. The relation of implication wouldn't be false provided that one of the propositions of the precedent was false ${ }^{7}$. To put in another way, logically, the conclusion could be true even with a false precedent. This shows the difference between logical formalizations and the inferential process of the practical reasoning, and it also shows the need (outside of the logic) that every precedent is actually true. In this relation between merely formal reasoning and practical reasoning, we can, in other formalization, probe such consequences. From the same content of propositions (1.a), (1.b), (1.c), and (1.d), let's see the following relation between precedent and consequent:

$$
\left(q^{\wedge} \mathrm{r}\right) \vdash(\mathrm{p} \rightarrow \mathrm{s})
$$

6 Cf. Broome, J., 2009, p.76-84.

7 According to the rule of conjunction, if one of the propositions is false, every conjunction becomes false, and, thus, every precedent also becomes false. The implication wouldn't be false, even if it was counterintuitive. This counterintuitive aspect is part of the consequences of the paradoxes of material implication. 
- where $\mathrm{p}=(1 . \mathrm{a}) ; \mathrm{q}^{\wedge} \mathrm{r}=(1 . \mathrm{b}$ compound proposition $), \mathrm{s}=(1 . \mathrm{c}$ or $1 . \mathrm{d})$ and $\vdash$ means "therefore...".

- where we read: if (1.b) there is an elder facing hardship to cross the street, and I am able to help him, therefore, if (1.a) my action must be considered a universal maxim, so, (1.c) I help him cross the street (description of an action), or (1.d) I must help (description of a mental state or intention).

In this last case, the determination found on proposition "p" (1.a), which is arising from an ethical reflection, was put on the consequent and cannot be false, under the condition that all conditional is false. The problem here is that the determination, of an ethical nature, does not play its role of supporting the conclusion, which occurs when it is part of the precedent as in the previous example. In the second example above, the ethical proposition is part of the conclusion.

It is important to notice that the paradoxical character of the material implication plays against the ethical influx in the conclusion. For the conclusion comprising two propositions under the operator of the material implication, allows the proposition "p", of ethical nature, to be false, and even so, the conclusion, of the entire argument, will be true. For that reason, the importance of the proposition of ethical nature ("p" or (1.a)) influences on the reasoning itself and demands that the relation is only a conditional relation and not material implication. In the conditional relation " $p \rightarrow s$ ", " $p$ " and "s" must be true. For " $p$ " is true due to its ethical background, and "s" is true due to the practical character of the reasoning. Another way to analyze this conclusion would be by the use of a conjunction: " $p^{\wedge} s$ ", where both propositions must be true so that the conclusion of the reasoning is also true. However, this would weaken "p" and also the ethical determination contained in the conditionality: "if..., then...".

The logical resource highlights the importance of the ethical determination involved in the logical operations of a practical reasoning with ethical background. Whether in the first example or in the second, the ethical determination orients the comprehension of the conclusion and it is on the base of practical reasoning in the area of ethics.

Another way of approaching the sorts of practical reasoning in the field of ethics is to add reasons to the propositions. These reasons would depend on an ethical reflection, which would consist in a theory of the practical character of reason and, thus, this theory would lead the reasoning to a moral field. In the following example, the proposition which is in the conclusion (2.d or 2.c) illustrates this possibility. We can affirm that, once this conclusion is obtained, a very specific interpretation of rationality is at stake. This interpretation of rationality explains the action, or the obligation of an action, or the intention of an action. These possibilities are results of the connection between practical reasoning and a specific interpretation of human rationality, which also includes the influence of a philosophical perspective.

Let's see these examples:

(2.a) There is an elder facing hardship to cross a busy street.

(2.b) I am able to help him.

(2.c) I help the elder cross the street (description of an action) or,

(2.d) I must help him cross the street (expression of an obligation). 
In this case, the formalization is this:

$\left(\mathrm{p}^{\wedge} \mathrm{q}\right) \rightarrow \mathrm{r}$

-where $\mathrm{p}=(2 . \mathrm{a}) ; \mathrm{q}=(2 . \mathrm{b})$ and $\mathrm{r}=(2 . \mathrm{c})$ or $(2 . \mathrm{d})$.

-where we read: "if there's an elder facing hardship to cross the street and I am able to help him, then I help him (I must help him)".

In the example (2), the proposition (2.b) adds a reason so that (2.c) or (2.d) fulfilled. This added reason is not expressed in the reasoning, what is expressed is the specific proposition of the reasoning which refers to the support of the interpretation of rationality, which is arising from a specific ethical reflection. So, from this ethical reflection, there is an inflection point which forcibly operates on the reasoning by an external point. It is a divergent case from the previous one, when the ethical determination was expressed between one of the propositions, therefore, internally. In the example (2) above, the determination remains underlying and external. The conclusion expresses the action, which can be considered as moral and, this expression ends the reasoning.

According to these considerations, we are able to say that, elements which are not presented in the thread of premises support the conclusion (whether it is proposition 2.c or 2.d). This underlying support accepts that, the fact that the agent has reasons, they are reasons to act, so the agent must act. We can notice here that such reasons are more important than the presented facts in (2.c) and (2.d) themselves, imbued of importance, they remain underlying in the thread of premises (precedent and consequent). Furthermore, one of the facts: (2.c), "I am able to help him" adds a connection to an external reason, sustainer of an action classified as "moral". It is possible to affirm that there is a rational normativity in the thread of the facts in the reasoning, but this normativity wouldn't be a moral factor itself. To transform this normativity, which is inferential (and even merely formal), in a moral one, it is necessary to develop a theory of the action. It means we have to add something to the action. This something is more than the mere finding of a fact.

To affirm that both facts presented: "there is an elder facing hardship to cross a busy street" and "I am able to help him", result in the conclusion: "I help him" or "I must help him", will show a gap in the inferential process between the precedent and the consequent, such gap will only be solved by the interpretation of the agent's rationality and the practical character of this rationality, that is, by a theory of the action which is implicit. The facts (2.a) and (2.b) need this implicit support to get to a conclusion (2.c or 2.d). The gap is filled by the comprehension of the roles that perform the reasons and the rationality of the agent on his practical behavior in face to such situation. It is a "reason imperative" that rules the will of every rational being ${ }^{8}$.

The practical reasoning is put in service of the external interpretation that transforms the proposition (2.b), which deals with the facts, in a reason to act. Therefore, the action becomes moral. The core of the external ethical determination is the assumption that this proposition (2.b) "I am able to help him" brings along the reason to such action, and the agent responds to it, acting.

8 Here, we have an ethical determination arising from a matrix of thinking, which is identified to Kant's philosophy, and not an engagement to a humean theory, for it, we would need a premise that adds the following information: "I feel motivated to act due to a certain feeling". 
The argument (2) has the following situation: there is an (external) impediment, in which the proposition of the conclusion is false otherwise there would be a disagreement with the action or the practical rationality theory. On the other hand, if the precedent is false (a disguised actor playing the role of an elder facing hardship to cross a busy street), even so, the conditional would be true, because the conclusion is true (2.c or 2.d: "I help him" or "I must help him"). It illustrates the distance between logical resources in relation to inferential processes required for practical reasoning. On this matter, one of the theorists of the practical reasoning Douglas Walton, agrees with such distance:

Practical reasoning is essentially pragmatic because it is not the formal validity of the argument structure that is at issue in evaluating a particular case. Instead, if the two premises of scheme are satisfied in a situation, a burden of proof is thrown on the critic who rejects the conclusion to pose an appropriate critical question. ${ }^{9}$ (Walton, 1992, p.999).

The burden of proof of a critical conclusion, in a practical reasoning, faces the pragmatic character revealed in the conclusion. In spite of this difference between logical and practical reasoning, the clear impossibility of an effective appliance of logical formalization ${ }^{10}$ makes the reasoning structure more visible on its susceptibility to the strength exerted by the ethical reflection. It is interesting that this external influence transforms the effectiveness of practical reasoning in a moral effectiveness. However, in its effectiveness an philosophical basis, the ethical reflection has its diversity and can refer to different matrices of philosophical thinking ${ }^{11}$.

Both arguments in examples 1 and 2, above, are examples of the use of practical reasoning applied in the moral field. The interface of these logical resources has opened the way to analyzing two sorts of ethical determinations: the internal one, in example 1, and the external one, in example 2. To say it in another way, despite the fact that in this two cases the practical reasoning might be considered as "moral-practical", we can show that not every practical reasoning is "moral-practical". The areas of common sense and programming languages also use practical reasoning, where there is no ethical determination, so there is no influence from an ethical base. The persistence in considering practical reasoning only as connected to ethics would represents a reductionism in the moral field which would deny, or even would usurp, the philosophical thematization of practical reasoning in other fields. In the next section, we will present these fields in your not-so usurped.

9 And also, p.998: "Practical reasoning fits the missing parts into the collection of means-end sequences that represents the agent's knowledge of what is possible and plausible - in short, his plan of action." Douglas Walton is an author with a wide work on Argumentation, Practical Reasoning and Artificial Intelligence.

10 We use only propositional logic in our examples. We don't use symbolic logic or modal logic resources. Regarding this issue, inside modal logic, we must highlight the deontic logic from Von Wright. In this case, we underline his work on practical reasoning in Von Wright, H-G.. "On So-Called Practical Inference". 1972, p.49s. However, the deontic logic approach demands a deepening beyond this article scope, for it would move away from the macro reach of the knowledge areas. The specification, through deontic logic, must be done in another work.

11 It is the case of the following ethical examples: a matrix with Kantian, neo-hobbesianism, humean or even aristotelic background. 


\section{The second group: the instrumental practical reasoning}

The practical reasoning mode, in the second group, covers two areas: the common sense and the programming languages. This union of both fields in only one group can be justified by a shared identity, but not fully. The justification for their sharing in only one group is in the relation of means and ends. And the difference between them is on the base which sustains this relation, as we will see below. The general classification of this shared mode of the relation means and ends can be expressed by the adjective "instrumental".

In the case of common sense and programming language areas, the relation means and ends is the operational core of the necessary means of an action. And this action is the fulfillment of an end proposed in a specific and well-determined problem. The agent, whether artificial or human, ratiocinates and performs an action, which configures a practical reasoning.

The operational core assumes the relation through the fixation of an end and verifies the means to its fulfillment. This core, oriented by the relation means and ends, fills the gaps between the precedent and the consequent, not allowing any external determination on the proposition of the reasoning. The operational character of the reasoning execution by an agent endorses the adjective instrumental. We can see a possible definition for this sort of reasoning in John Broome's perspective:

Your reasoning process is a particular type of practical resoning. It is instrumental reasoning, which means it is concerned with taking an appropriate means to end. [...]. There are other sorts of practical reasoning too, but if we want to understand practical reasoning, it is a good idea start with instrumental reasoning, because it is less controversial than other sorts. (Broome, 2002, p.86).

The point we underline, on its instrumental sense, is that the practical reasoning has the scope of internal elements subsumed by "taking an appropriate means to end". This submission demonstrates the unity between the common sense and programming areas. To clarify this, we need to make an observation on the scope of reasoning in general, reviewing what we have said about the first group of ethics.

In the first group, the field of ethics is unilaterally assumed, and the scope is different. The example (1) has on proposition (1.a) the announcement of a moral maxim, and it determines the scope, the expression of this maxim is beyond reasoning. In example (2), the passage from the precedent to the consequent evidences a gap. Moreover, this gap suffers the ethical determination which, on its external and implicit form, detaches itself allowing such inferential passage and the arrival of the reasoning conclusion.

In the practical reasoning from common sense and programming languages, the scope is reduced to the proposed end. The reducer character of the scope is a shared characteristic of both areas. But, we can notice a difference in the details of the argumentation process. It will be explained hereafter through examples.

The first example, in the area of common sense, is a modified version used by many authors, as follows:

(3.a) It is raining.

(3.b) I want to go to the train station two blocks from my house. 
(3.c) I take an umbrella (description of an action) or

(3.d) I want to take an umbrella (I have the intention).

The example shows that the conclusion in (3.c) or (3.d) expresses a mean to reaching an end. This conclusion can be an action (3.c) or an intention (3.d). Both possibilities of conclusion are determined by the end in (3.b). And the reasoning has its scope closed according to such end. The action, or intention of an action, presented in conclusion (3.c) or (3.d) shows the achievement or direction of a mean. It differs from ethics, since there is no specific determination, arising from an ethical reflection, internal or external to the practical reasoning.

The absence of an underlying ethical reflection is shown in (3.b). The proposition of (3.b) reveals only a will or intention. However, it is possible to object that there is a reason not explicit to the conclusion and, therefore, to the inferential passage that begins from (3.a) and (3.b) and goes to (3.c) or (3.d). This "reason not explicit" would be something like "An umbrella serves to protect us from the rain". The "reason not explicit" belongs to the set of true beliefs of the agent. And, in this case, the set of beliefs has, as a background, an epistemological reflection, not an ethical one. However, it is a discussion which will not take place here.

The formalization of the example is:

$\left(\mathrm{p}^{\wedge} \mathrm{q}\right) \rightarrow \mathrm{r}$

-where $p=(3 . a) ; q=(3 . b)$ and $r=(3 . c$ or 3.d as either action or intention).

The propositions "p" and "q" ("it is raining" and "I want to go to the train station two blocks from my house") must be true so that the conclusion is also true, and the process, as a whole, logically true. Including in this case, similarly to the previous examples, the logical validity is detached from the practical reasoning, for even if the propositions " $p$ " and "q" are false (therefore, if every precedent is false) and the conclusion true, the reasoning would be true and valid. Once again we are considering only the conditionality and not a material implication. One example of this situation would be: “- if... is false that is raining and it is false that I want to go to the station two blocks from my house..., then... I take an umbrella..." Pragmatically this is irrational, but logically true. The opponent against this practical reasoning mode, which has the burden of proof, would have to show that it is not pragmatically irrational to take an umbrella under the circumstance in which I don't want to go to the station and it is not raining.

In the common sense area we can say that the practical reasoning fastens itself in a specific point. The agent defines the end and pursuits the required mean to reach it. The definition of an end approaches him/her to the practical egoism and a self-concern calculation, where the resource of probability can be used to analyze the means that lead to the fulfillment of the end.

There is an opening to ethics in this egoism ${ }^{12}$, but this opening is not originating, but derived from the instrumental condition. Yet, regarding the instrumental plan of practical reasoning, the ethical egoism enlarges the scope beyond the premises of the reasoning.

12 The exposure of different approaches of "ethical egoism", under a neo-hobbesean influence, can be found on David Gauthier's book: Gauthier, D. Morals by agreement. Oxford: Oxford University Press, 1986, p.157-189. Differently, but still under a neo-hobbesean matrix, there is: Baier, Kurt. The Rational and the Moral Order: The Social Roots of Reason and Morality. Chicago: Open Court, 1995, p.159-173. 
That is, it goes further the restrained concern of the reasoning and orients itself by another underlying wider concern (derived from an ethical tendency). The operational and instrumental character of the practical reasoning, on the other hand, reduces the reach, focusing the conclusion on the most suitable mean, without any other influent determination, as the ethical reflection. It shows, once more, that the characteristic of ethics is to work with a different scope from the relation means and ends expressed on instrumental reasoning.

The decision of the agent on behalf of one mean to another depends on a background that thematizes the problem to be solved. This factor has the prior characteristic of intelligibility, which is thematized in a philosophical way, because it is a furtive element and, on its furtive quality, it acquires a possible treatment, but not necessarily in the ethical reflection. It is, ultimately, dealing with the existence of a background ${ }^{13}$. From this background the agent is able to decide his action. The agent deals with the available and exact means, generally used to deliberate or access the most suitable means to each end. Thus, occupied by immediate problems, the common sense has a reduced scope.

The other example of this group is the one inferred on programming languages. The relation means and ends remains, in this case, as main element of the operational core of the reasoning. The difference is that, in the common sense, the end (to be reached) is in the thread of premises and, therefore, dominates the whole scope of the reasoning. Nevertheless, regarding the programming languages, the scope of the reasoning refers to beyond an immediate, limited situation. This means that the resolution of a problem occurs by the acceptance of an unpredicted problem, and its ulterior division in several other problems, configuring the biggest and the smallest. The consequence is that the end loses its reducer fixed form and the process becomes more complex with such division.

The programming languages which work on practical reasoning are the ones connected to developments of Artificial Intelligence. These languages from A.I. deal with unexpected problems until certain level. The fragmentation of an unexpected problem in many other smaller problems implies the respective division of the pursuit end in smaller ones, creating new specific stages of execution. Each stage constitutes a new end and a new problem, however smaller ${ }^{14}$. From an external perspective, the general processing depends on the resolution of the end originally proposed (the one which was divided). The program starts such division and searches for alternatives face the unexpected.

This is an example of practical reasoning on its use by the programming languages ${ }^{15}$ :

13 The action of an agent in the Artificial Intelligence is given in a furtive form according to the software architecture in which this agent is built. The main architectures are: reactive, deliberative and hybrid. Cf. Wooldbridge e Jennings, 1995, p.130, 132 e 134.

14 Cf.: Nilsson, J. Nils. Problem-Solving Methods in Artificial Intelligence. McGraw-Hill, 1971: "A somewhat more sophisticated problem-solving approach involves the notion of subproblems. In the approach, an analysis is made of the original problem in order to produce a set of subproblems such that solutions to some particular subset of the subproblems such that solutions to some particular subset of the subproblems would imply a solution to the original problem." (p.5).

15 This example was inspired by Steels, L. "Cooperation between distributed agents through self organization". In: Demazeau, Y.; Müller, J. P. (eds.). Decentralized AI: Proceeding of The First European Workshop on Modelling Autonomous Agents in Multi-Agent World. Amsterdam, 1990, p.175. In the original example of Steels, there are agents, in independent vehicles and different points, exploring a distant planet without a detailed map. They must move, communicate and overcome obstacles. 
(4.a) the robot X-1 is an independent agent and must travel through a narrow path in Mars until point 10-10, where there is a clearing where it can collect samples. This robot has a mapping based on simple Cartesian axis.

(4.b) the robot X-1 is performing the action described above, when in point 8-8, it visualizes a landslide on its narrow path, blocking its progress.

(4.c) the point 8-8 has only one bifurcation on the right, which is still unexplored by robot X-1 and, it doesn't have data about this area.

(4.d) the robot X-1 must decide whether to travel through the bifurcation or return to base.

(4.e) the robot consults its own data bank, but there is nothing programmed on this respect, except by the order to start a research process with other agents involved in the exploration of this planet (or other robots, satellites or other sensors). This robot has a communication platform with the other agents, such platform is developed in a determined programming architecture. The classification of these architectures originally present three possibilities: deliberative, reactive or hybrid. In this case, our robot cannot have a reactive programming architecture because all its research and decisions would be previously programmed and it wouldn't deal with unexpected situations. Furthermore, a reactive programming would demand spend of time in communications with Earth.

And (4.f), the robot X-1 has the following options based on incomplete data about the unknown path on the right: it can either (4.1.f) travel through the bifurcation path on the right. In this case, the data regarding the landslide, obtained from other artificial agents, wouldn't indicate any major threat in the decision to go by an unknown path, in addition, the robot would use its sensors to travel through such path; or (4.2.f) the robot wouldn't accomplish its aim of reaching point 10-10 and would return to base. In this case, the data obtained, although they contain new information which need to be processed by X-1, reach a dangerousness-level that is not tolerable in the security protocol, consequently, the proposed end on point $10-10$ is not achieved.

Let's analyze in details the argumentative structure of the practical reasoning:

- First part: from 4.a to 4.d;

- Conclusion of first part: 4.d;

- Second part: from 4.e to 4.f;

- Conclusion of second part: 4.f;

- The consultation with other agents start in 4.e and it represents the access to a new set of data, in the form of new propositions about the initial problem, generating the division of this problem in several parts; the new set of data consists of information passed by other agents. The small problems, which come along the information from other agents, must contribute as hallmarks of dangerousness-level regarding the decision of following or not the unknown path. The information is passed and translated in new premises, which must have conclusions that make robot X-1 progress or not. Besides, the new information help evaluate the danger of the path. The decision to go on or not depends on the comparison between the as beacons of dangerousness-level and the importance of achieving the end. It is important in example (4) the potentially deferrable end and the beginning of a consultation with other agents. Each new stage 
on the bifurcation path, if it is the path chosen by the robot, is a small problem to be solved, because the ambit of the incursion became unknown.

In the programming languages, there is no determination of an ethical proposition, whether it is internal or external. And there isn't a relation reduced to a circumstance which configures the whole problem either. It means that the scope of the major problem is restricted, because the end, put on the major problem, can be postponed and divided in smaller problems with smaller ends. Furthermore, it is still possible to exist a platform of multi-agents that helps the resolution of an unexpected problem through consultation and gathering of new data.

The decision process of robot X-1 also requires the information acquired on the exchange of data with other agents. The connection of robot X-1 to the other agents can be illustrated by the theory of games ${ }^{16}$. The work and survival process of the agents is cooperative and the relation between them tends to a balance and a strategic positioning ${ }^{17}$. The multi-agents platform performs the task of exchanging information to meet the requirements of an action to be executed. We can also understand the relation of robot X-1 with the other agents as a egoist relation. The theory of games contemplates such possibility, where each player contributes with the other, but not giving up from their own specific aims.

The examples (3) and (4), presented on this section, show sorts of practical reasoning that highlight the emphasis in the relation means and ends, and which have the action or a orientation to the action, as a result of the respective conclusions. As we presented earlier, this sort of reasoning can be called "instrumental practical reasoning" and it doesn't suffer external determinations which influence its inferential processes (as in ethics). This being said, we can present our conclusion.

\section{Conclusion}

The practical reasoning in general, cannot be considered as exclusively moral and subject to an ethical orientation. However, if it is so considered, the ethics will exercise a certain sidedness on the theme, depriving and dispelling other areas, where reasoning also pursuits an action. Considering every practical reasoning as moral-practical reasoning, or ethical reasoning, this is a mode to suppress the way to different sorts of reasoning that are present in our actual world.

The other forms of reasoning as the common sense and the programming languages don't have an ethical oriented reflection. Nonetheless, these areas develop reasoning that

16 Cf.: Nilsson, J. Nils. Problem-Solving Methods in Artificial Intelligence. McGraw-Hill, 1971, p.109-111.

17 One of the ways of explaining this balance is according to the theory of games, which is basically a mathematical approach. As orientation, we use in our example, an influence of Equilibrium from John Nash, where there is cooperation between participants of a game. In the history of the theory of games, Nash's proposal differs from the initial proposal of Von Neumann and Morgenstern (Cf.: Von Neumann, J.; Morgenstern, O. The Theory of Games and Economic Behavior. Princeton: Princeton University Press, 2004, Sixtieth-Anniversary Edition, 2004, p.31-43). It is important to consider the applied sophistication posterior to Nash's theory with the concept of "risk-dominance". (Cf.: Harsaniy, J. C.; Selten, R. A General Theory of Equilibrium Selection in Games. Cambridge: MIT Press, 1988, p.87). 
result in actions or intentions. We wanted, with this article, to show the importance in distinguishing, from ethics, the other areas regarding the practical reasoning issue. Furthermore, having this intention in mind, we wanted to open the way to a plurality in the discussion of the practical reasoning issue and the insertion of new debates, which become pressing, especially in the area of programming languages. This article presented, through examples, the differences mentioned above, configuring a new start to rich future discussions on the practical reasoning issue.

\section{References}

ALLAN, D. J. (1955): “The Practical Syllogism”. In: MANSION, S. Autour d'Aristotes. Louvain.

BAIER, Kurt (1995): The Rational and the Moral Order: The Social Roots of Reason and Morality. Chicago: Open Court.

BRATMAN, M. E. (1987): Intentions, Plans, and Practical Reason. Cambridge: Massachusetts University Press.

BROOME, J. (2002): "Practical reasoning”. In BERMÙDEZ, J.; MILLAR, A. (eds.). Reason and Nature: Essays in the Theory of Rationality. Oxford: Oxford University Press, p. 85-111.

BROOME, J. (2005): "Have We Reason to Do as Rationality Requires? A Comment on Raz". In: Journal of Ethics and Social Philosophy. Volume 1, Symposium I, issue 1, April. http://www.jesp.org/articles/

BROOME, J. (2009): "The Unity of Reasoning?", in ROBERTSON, S. (ed.) Spheres of Reason. Oxford: Oxford University Press, p. 62-92.

GAUTHIER, D. (1986): Morals by agreement. Oxford: Oxford University Press.

GAUTHIER, René Antoine; JOLIF, Jean Yves (1959): L'Etique a Nicomaque (comentaire). Paris: J. Vrin, vol. 1 y 2.

HARSANIY, J. C.; SELTEN, R. (1988): A General Theory of Equilibrium Selection in Games. Cambridge: MIT Press.

KNAPIK, M.; JONHSON, J. (1998): Developing Intelligent Agents for Distributed Systems: Exploring, Architecture, Technologies, and Applications. MacGraw-Hill.

NILSSON, J. Nils. (1971): Problem-Solving Methods in Artificial Intelligence. McGrawHill.

RAZ, J. (2005 a): "The Myth of Instrumental Rationality", Journal of Ethics and Social Philosophy. April. http://www.jesp.org/articles/

RAZ, J. (2005 b) “Author's Reply: Joseph Raz, 'Instrumental Rationality: A Reprise””. In: Journal of Ethics and Social Philosophy, Volume.1, Symposium 1, issue 1. April, http:// www.jesp.org/articles/

RUSSELL, Stuart; NORVIG, Peter. (2010): Artificial Intelligence: a modern approach. New Jersey: Prentice Hall, $3^{\mathrm{a}}$ ed. [tradução portuguesa RUSSEIL Stuart; NORVIG Peter. Inteligência Artificial. Rio de Janeiro: Elsevier, 2004. Tradução de Vandenberg D, de Souza]. 
STEELS, L. (1990): "Cooperation between distributed agents through self organization". In: DEMAZEAU, Y.; MÜLLER, J. P. (eds.). Decentralized AI: Proceeding of The First European Workshop on Modelling Autonomous Agents in Multi-Agent World. Amsterdam, p.175-196.

STREUMER, B. (2010): "Practical Reasoning”. In: O'CONNOR, T.; SANDIS, C. (eds.) The Blackwell Companion to the Philosophy of Action. Oxford: The Blackwell Publishing, p. 244-251.

VON NEUMANN, J.; MORGENSTERN, O. (2004): The Theory of Games and Economic Behavior. Princeton: Princeton University Press, Sixtieth-Anniversary Edition.

WALTON, D. (1992): "Practical Reasoning". In: BECKER, L. C.; BECKER, C. B. (eds.). Encyclopedia of Ethics. New York: Cambridge University Press, vol. 2, p. 996-1000.

WIGGINS, D. (2001): "Deliberation an Practical Reasoning". In: MILLGRAM, E. (ed.) Varieties of Practical Reasoning. Cambridge: MIT Press, p. 279-299.

WOOLDBRIDGE, M.; JENNINGS, N. (1995): "Intelligent Agents: Theory and Practice", Knowledge Engineering Review, January, v. 10:2, p. 115-152.

WRIGHT, von H-G. (1972): "On So-Called Practical Inference". In: Acta Sociologica v. 15, January, p. 39-53. 